\title{
Commentary: Left ventricular assist device and outcome: Where are we planning to go?
}

\author{
Alessandro Barbone, $\mathrm{MD}, \mathrm{PhD},{ }^{\mathrm{a}}$ and Michele Di Mauro, $\mathrm{MD}, \mathrm{PhD}^{\mathrm{b}}$

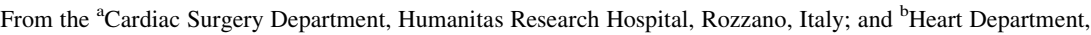
SS Annunziata Hospital, Chieti, Italy.

Disclosures: Authors have nothing to disclose with regard to commercial support.

Received for publication Dec 12, 2018; accepted for publication Dec 12, 2018; available ahead of print Jan 29 , 2019.

Address for reprints: Michele Di Mauro, MD, PhD, Heart Department, SS Annunziata Hospital, Via dei Vestiini, 66100, Chieti, Italy (E-mail: mdimauro1973@gmail.com).

J Thorac Cardiovasc Surg 2019;157:1863-4

$0022-5223 / \$ 36.00$

Copyright (c) 2018 by The American Association for Thoracic Surgery

https://doi.org/10.1016/j.jtcvs.2018.12.034
}

Thang and colleagues ${ }^{1}$ present a very interesting analysis of a large, long-term left ventricular assist device (LVAD) program, retrospectively reviewing their experience and apparently coming up with a clear message: Sicker and more worn out patients do worst. Or not?

It is clear that patients in the lower Interagency Registry for Mechanically Assisted Circulatory Support class have higher incidence of right ventricular failure (RVF) than patients with probably long-standing advanced heart failure (HF) proven by bilateral atrioventricular valve regurgitation, higher central venous pressure, and overall signs of left ventricle failure moved to the right heart. Although this does not correlate with long-term survival-either overall or to transplant. Is this a case of what the literature has long stated regarding RVF being false? ${ }^{2}$ Or does acute RVF not correlate with chronic, long-term RVF?

Most likely, 2 main factors demonstrate that the population being examined in the reported series in not representative of the real-world HF population: the average age is $55.16 \pm 13.1$ years and almost two-thirds of the population treated are bridge-to-transplant candidates. Thus, in this highly selected population, RVF can most likely be tolerated without affecting survival.

Is this what we want to do for the future? Is well known that HF incidence is highly correlated with age ${ }^{3}$ and comorbidities, and consequently the larger share of patients might seek LVADs as an alternative to a transplant that might never be available for them. Only when devices are unlinked to transplant will this therapy's potential be fulfilled. As clearly reported by Thang and colleagues, ${ }^{1}$ there is still debate regarding whether or not to treat mitral valve regurgitation (MR) and address other structural cardiac disease at the time of LVAD implant. Although it is pretty clear that there is an advantage to preserving aortic valve pulsation, ${ }^{4}$ it is not always recalled that the procedure requires ventricle loading and how consequent MR would negatively affect pulmonary pressure and the right ventricle. The reported series exemplifies this when it showed that in more than 158



See Article page 1851.

patients with severe MR only 1 mitral procedure was performed.

Could this be the time to stop thinking of LVADs as LV replacement therapy and to start using them as LV assist therapy? That is, a further step to partially support a failing ventricle to reach a fully functional LV? Above maximally tolerated drug therapy, above electrical correction therapy, above percutaneously approached valve failure? Elderly patients without any chances for transplant might highly benefit from a superficial (maybe percutaneous) partial support device. Very limited (at least promising) data were available before poor management and health policy rules killed the experience in the crib. , $^{5}$

We need to rethink the role of LVADs, the population that the device is intended to treat, and the timing of the implant. We also need to ask for and promote the development of new, dedicated devices if we are willing to move this therapy a step farther and really affect the population that needs it most to change the natural history of the disease worldwide.

\section{References}

1. Tang PC, Haft JW, Romano MA, Bittar A, Hasan R, Palardy M, et al. Cluster anal ysis of preoperative echocardiographic findings and outcomes following left ventricular device implantation. J Thorac Cardiovasc Surg. 2019;157:1851-60.e1.

2. Morgan JA, John R, Lee BJ, Oz MC, Naka Y. Is severe right ventricular failure in left ventricular assist device recipients a risk factor for unsuccessful bridging to transplant and post-transplant mortality. Ann Thorac Surg. 2004;77:859-63.

3. Benjamin EJ, Blaha MJ, Chiuve SE, Cushman M, Das SR, Deo R, et al. Heart disease and stroke statistics-2017 update: a report from the American Heart Association. Circulation. 2017;135:e646.

4. Marinescu KK, Uriel N, Mann DL, Burkhoff D. Left ventricular assist deviceinduced reverse remodeling: it's not just about myocardial recovery. Expert Rev Med Devices. 2017;14:15-26. 
5. Barbone A, Pini D, Rega F, Ornaghi D, Vitali E, Meyns B. Circulatory support in elderly chronic heart failure patients using the Circulite ${ }^{\circledR}$ Synergy ${ }^{\circledR}$ system. Eur J Cardiothorac Surg. 2013;44:207-12.
6. Meyns B, Rega F, Barbone A, Ornaghi D, Strueber M, Simon A, et al. Circulite ${ }^{\circledR}$ Synergy ${ }^{\circledR}$ system for the treatment of intermacs $\geq 4$ heart failure. $J$ Heart Lung Transplant. 2013;32(4 Suppl):S148. 